\title{
LAS MUJERES LACANDONAS: CAMBIOS RECIENTES
}

\author{
Lucie Nečasová
}

Resumen: El artículo se enfoca principalmente en los cambios en la vida de las mujeres lacandonas contemporáneas en las últimas decadas. Analiza cómo se han modificado el modo de la vida, las costumbres y las relaciones de la mujer dentro de las propias familias pero también dentro de la sociedad y la comunidad en general. El objetivo es mostrar los cambios importantes reflejados en la vida de las mujeres mediante de tres generaciones principales. El estudio está basado en las etnografías disponibles combinadas con el propio trabajo de campo realizado en las comunidades Lacanjá y Nahá en los años 2008 y 2009.

Palabras clave: Lacandones, mujer lacandona, cambios culturales, selva lacandona, Lacanjá, Nahá, poligamia, turismo.

Enviado a dictamen: 25 de enero de 2010

Aprobación: 15 de abril de 2010

Revisiones: 1

Lucie Nečasová, maestra en Teoría de la cultura, Facultad de filosofía de Universidad Carolina en Praga, República Checa. Temas de especilizacion: los lacandones, niños indigenas, trabajadores, cambio cultural. Correo lectrónico: lucienecasova@hotmail.com.
Abstract: This article is principally focused on cultural changes in the way of life of lacandon women in the last decades. It analyzes modification of the common life, the habits and the relationships in the families as well as in the society and comunity in general. The goal is to display the important changes of lacandon women lives which are reflected on three generations. The study is based on available etnographic studies combinated with (primary) (original) fieldwork realised in the communities of Lacanja and Nahá in 2008-2009.

Key words: Lacandons, lacandon women, cultural changes, lacandon jungle, Lacanjá, Nahá, polygamy, tourism.

\section{Introducción}

E propósito central de este artículo es señalar diversos cambios en las vidas de las mujeres lacandonas dentro de sus familias pero también dentro dela comunidad. En la primera parte del artículo se revisan diferentes etnografías que se habían escrito acerca de los lacandones en el siglo XX; en la segunda parte me dedico a los lacandones contemporáneos y los cambios esenciales en la vida de las mujeres. La información usada está basada en mi trabajo de campo realizado en dos comunidades (Lacanja y Nahá) en los años 2008 y 2009. 
El tema de las mujeres se empezó a discutir en la antropología principalmente en la segunda mitad del siglo XX. En los años setenta se empieza a dar más importancia a estos estudios para comprender mejor la diversidad de la sociedad y de la cultura en términos de las diferencias de poder entre hombres y mujeres (Narotzky, 1995). Según Pine, Friedl y Lamphere hablan de la división de las esferas pública y privada, donde las mujeres ocupan el lugar privado/doméstico y los hombres espacio público. A pesar de dicha división, Friedl señala que la línea no es tan estricta y que las mismas mujeres manejan sus propias estrategias para influir y negociar lo público a través de lo doméstico (Pine, 2002). También señala que Rosaldo menciona que la esfera doméstica representada por mujeres era por lo general subordinada de la esfera pública representada por los hombres; sin embargo la extensión del poder depende del grado de la separación entre las dos esferas (Pine, 2002).

Como el tema es mucho más complejo y es difícil mostrar dónde termina lo privado y donde empieza lo público surgió el estudio del género, el cual se enfoca mucho más en las relaciones entre los hombres y mujeres, y se dedica más a ver las diferencias de lo dominante y lo subordinado en el contexto social (Pine, 2002). Según Escalona (2009) lo principal que cruza el mundo dominante y subordinado en las familias es el poder, por lo general representado por una autoridad masculina. Sin embargo, también habla de que el tema es más complejo y hay que ver las relaciones de manera más amplia, porque las dinámicas de poder no se reflejan solamente en la relaciones entre la mujer y el hombre sino también en otras relaciones intrafamiliares, madre e hija, nuera y suegra, etcétera. Sin embargo, el objetivo de mi artículo no es representar las distintas teorías que hablan de los estudios del género; más bien se trata de señalar los importantes cambios que han ocurrido en la sociedad lacandona a través de las pequeñas biografías de las mujeres en tres generaciones principales: las mujeres mayores, las adultas y las jóvenes. Aunque aquí se presentan algunos elementos de las relaciones de las mujeres y los hombres en las esferas pública y doméstica, el artículo se enfoca más en el registro de los cambios en la vida de las mujeres que en el análisis de los cambios en las relaciones de género.

\section{Las comunidades lacandonas}

La selva lacandona se ubica en la parte noreste del estado de Chiapas, México, y se extiende al sureste hasta la frontera con Guatemala. Está localizada en el centro del área de población maya de México y Centroamérica. La región está delimitada al norte, este y sur por los ríos Usumacinta a Chixoy, y al oeste por los ríos Santa Cruz, Jataté y Santo Domingo. Toda el área ocupa aproximadamente 19 mil 789 kilómetros cuadrados y está integrada mayoritariamente a siete municipios: Altamirano, Chilón, Las Margaritas, Ocosingo, Benemérito de Las Américas, Maravilla Tenejapa y Marqués de Comillas. Actualmente en dicha región viven aproximadante 200 mil habitantes; $65 \%$ son de diferentes grupos étnicos, especialmente tzeltales, tojolobales, tzotziles, choles y lacandones (hablantes de variantes de lenguas mayas) y el resto son campesinos no indígenas (Nolasco y col., 2008).

Los pueblos lacandones se encuentran en la parte norte de la selva. Actualmente viven de manera permanente casi 1,100 lacandones en cinco comunidades: tres en el sur (Lacanjá Chansayab, Betel y San Javier) y dos en el norte (Nahá y Metzabok) (Kováč, 2000).

\subsection{Lacanjá Chansayab}

Lacanjá Chansayab es la comunidad lacandona más grande y está constituida por tres asentamientos: Lacanjá, Betel y San Javier. Está ubicada cerca de las ruinas mayas de Bonampak entre dos reservas naturales: La Cojolita y la Reserva de la Biósfera de Montes Azules, en el río Lacanjá. En las tres comunidades lacandonas del sur viven un total de $719^{2}$ personas: en el pueblo de 
Lacanjá viven $425^{3}$ personas con 111 jefes de familia, 154 son mujeres mayores de 12 años y 16 con más de 50. En estas cifras se incluyen 16 mujeres no lacandonas que se casaron con habitantes de la comunidad y que viven dentro de ella. La mayoría de las mujeres no lacandonas residían en dos comunidades cercanas: Nueva Palestina (comunidad tzeltal) y Frontera Corozal (comunidad chol). Dentro de la población existen también: una mujer de Oaxaca, una de Veracruz (dos estados vecinos ubicados al poniente y al norponiente respectivamente) y dos de la ciudad de San Cristóbal de Las Casas, en el centro del estado de Chiapas (información obtenida en la clínica de Lacanjá Chansayab, marzo 2009).

\subsection{Nahá}

Nahá se ubica dentro del área de proteción de la fauna y la flora de Nahá y Metzabok, creada en el año 1998. La comunidad se encuentra al sur de Palenque y al noroeste de Ocosingo. Se ubica dentro de un sistema lagunar con la laguna principal de Metzabok y la laguna de Nahá. Actualmente Nahá está rodeada en ambos lados por varios pueblos tzeltales. Dentro de la comunidad hoy viven $232^{4}$ habitantes con 67 jefes de familia. Se tiene una población de 71 mujeres mayores de 12 años (ocho de ellas con más de 50). Ocho mujeres son no lacandonas, casadas con habitantes de la comunidad y la mayoría viene de los pueblos tzeltales cercanos a esta población.

\section{Generalidades sobre los lacandones}

Los lacandones son presentados hasta hoy por varias agencias de viajes, algunos autores de libros sobre la región y viajeros, como los últimos mayas auténticos, quienes por muchos años no tuvieron contacto con la gente de fuera y habían vivido muy aislados del mundo exterior. Esta imagen no ha influido solamente en los visitantes que vienen a buscar a los mayas verdaderos, también los lacandones mismos acomodan su comportamiento frente a los visitantes a ella (McGee, 2001).

Se puede decir que los lacandones, a diferencia de los otros grupos étnicos en Chiapas, no estuvieron bajo la influencia directa de los españoles, no vivían en pueblos permanentes sujetos al gobierno de la corona de España ni solían trabajar como peones en las fincas (grandes propiedades agrícolas) o en las plantaciones del café o en las empresas de maderas preciosas desarrolladas en el siglo XIX. Sin embargo, ya a finales del siglo XVIII los lacandones mismos empezaron a buscar contactos externos para comerciar. Cambiaban productos de sus milpas por cosas de uso cotidiano como sal, machetes, sábanas (Tozzer, 1982; McGee, 2001; Calderón, 2003 [1793]). Los contactos se intensificaron durante los siglos XIX y XX por la explotación de maderas preciosas en el área y por la incursión paulatina de los primeros antropólogos, misioneros, etnólogos, botánicos y los buscadores de chicle. Se supone, incluso, que los mismos lacandones no son originalmente de esa región sino que llegaron a habitarla durante los siglos XVII y XVIII (de Vos, 2006; McGee, 2001; Boremanse, 1998).

Con base en las diferencias culturales, étnicas y lingüísticas, los antropólogos y etnólogos dividen a la sociedad lacandona en dos grupos principales: uno del sur y otro del norte (Kováč, 2000). En el pasado los lacandones del sur se dividían en dos subgrupos principales, uno que vivía en el río Jataté, en el área de San Quintín, a un costado de la laguna de Miramar, en el centro de la selva lacandona, y otros que poblaron en la desembocadura del río Lacanjá (Boremanse, 1998). En contraste, los lacandones del norte vivían en un área amplia que se extende desde el río Jethá hasta el río Santo Domingo Chocolhá. El territorio se extendía en torno a la laguna de Nahá, y de las lagunas de Metzabok y Puná (hoy Monte Líbano) en la parte norte de la selva lacandona (Duby, 1961).

Hay que mencionar que en el pasado, los lacandones no solían vivir en pueblos permanentes sino en clanes 
familiares, llamados caribales, dispersos en la selva. Los caribales particulares estaban alejados uno del otro por varias leguas y los contactos mutuos entre ellos se reducían a intercambiar cosas y mujeres. Al frente de cada caribal estaba una autoridad masculina. Por lo general era el hombre el que demonstraba conocemientos religiosos profundos por lo que era respetado por los demás. Según Boremanse, había diferencia en el estatus de la autoridad entre los lacandones del sur y del norte. Él describe la autoridad del norte como t'oh'il, la persona tranquila y sesuda con capacidad de comunicarse con los dioses; mientras el carácter de los jefes del sur estaba conectado con la agresividad, el poder y el uso de brujería (Boremanse, 1998).

Los lacandones contemporáneos ya no viven dispersos en la selva sino en pueblos permanentes. En los años 40, por la migración de campesinos de otras regiones de Chiapas y del sur y centro de México se fundaron las primeras tres comunidades: Lacanjá Chansayab, Nahá y Metzabok. Sin embargo, no todas las familias vivían dentro de las comunidades. Muchas de ellas todavía buscaban la manera de vivir indipendientes y trataban de evitar los contactos con los demás (Marion, 1999).

En la década de los setenta, a causa de la evangelización, algunas familias del norte, especialmente del pueblo Metzabok, se convirtieron a religiones protestantes; a consecuencia de eso se fueron a vivir al sur, donde la nueva religión ya había sido aceptada. Estas familias refugiadas fundaron dos nuevas comunidades: Betel y San Javier. En la misma década, debido a la deforestación extrema, el gobierno mexicano creó la Zona Lacandona y decidió otorgar 614 mil hectáreas de tierra a los lacandones (exactamente a los 66 jefes de familia), "a los últimos mayas auténticos". Sin embargo, el gobierno puso una condición para otorgar la tierra: que todos los lacandones que todavía vivían dispersos en la selva se concentraran a vivir en los pueblos permanentes (Trench, 2002).

\section{Presencia de la mujer y los cambios: las etnografías del siglo XX}

A pesar de los varios informes que se conservan, de los siglos XVIII y XIX, en ellos no aparecen muchas referencias acerca de la vida de las mujeres de este periodo. Los viajeros y los primeros investigadores que hablaban de los lacandones se enfocaban más en la religión y las ceremonias vinculadas a ella. Es evidente que el contacto con las mujeres era difícil y bastante limitado por los miembros masculinos de cada caribal familiar (Blom, Duby, 2006). Las referencias hechas por los hombres-investigadores salen más como descripciones de la vida cotidiana y de las tareas visibles de los hombres y de las mujeres. Sin embargo, algunos antropólogos fueron a la selva acompañados por sus esposas y ellas empezaron a hablar un poco sobre la vida de las mujeres; además, los estudios de las mujeres y después del género no eran el tema central, pues empezaron a desarrollarse hasta en la segunda mitad del siglo XX (Narotzky, 1995).

Por eso nos enteramos más profundamente al mundo de las mujeres con la llegada de las primeras investigadoras, como Gertrude Duby y Marie-Odile Marion, en la segunda mitad del siglo XX. Vamos a revisar algunas referencias sobre las mujeres en las observaciones de Alfred M. Tozzer, a principios del siglo XX, Jacques Soustelle en los años 30, Gertrude Duby en la epóca de los años 40 hasta los años 60, Didier Boremanse en los años 70, R. Jon McGee en en la década de 1980 y Marie-Odile Marion en los años 90. Hay que mencionar que Marion fue la primera investigadora que se enfocó en el tema de las mujeres en específico, en algunos de sus trabajos. Además, hay que señalar que las notas sobre las mujeres hechas por los autores, especialmente en la primera mitad del siglo XX, cuando los lacandones no vivían en pueblos permanentes, ofrecen información contradictoria, pues dependieron de los caribales que visitaron los investigadores. 
Uno de los primeros autores que describe brevemente a las mujeres lacandonas es el antropólogo, arqueólogo y lingüista americano Tozzer. Dice: "Las mujeres lacandonas son casi tan fuertes físicamente como los hombres, frecuentamente cortan la madera para el uso de la familia y ayudan a sus maridos a limpiar la selva y a preparar la tierra para la siembra" (Tozzer, 1982: 41-42).

Cinco décadas después, aproximadamente, Duby (Blom, Duby, 2006) menciona que las mujeres lacandonas por lo general no trabajaban en la milpa con los hombres, sino que se dedicaban a las tareas domésticas. "La mujer hace la comida, cose los vestidos, atiende a los hijos y cuida de las gallinas" (Blom, Duby, 2006: 61). También agrega que la mujer es físicamente muy fuerte y sin problemas puede cargar bultos y niños, de manera simultánea. Además apunta que al igual que los hombres, las mujeres solían ya desde chiquitas fumar los enormes puros. Duby reporta que el carácter de las mujeres del norte y del sur era distinto. Sobre las mujeres del sur, menciona: "hablan con la misma franqueza que el hombre, tratan al forastero sin ningún temor y se ofrecen al hombre que les gusta sin el menor prejuicio" (Blom, Duby, 2006: 164). También apunta que la belleza física de este grupo era algo fuera de lo común.

Alfinalizar el sigloxX, Marion visitólas comunidades lacandonas cuando ya vivían en comunidades permentes y señala que las mujeres casi no salen de sus casas sin la compañía de sus esposos o al menos de otrofamiliar. Dice que su mundo social está limitado por el mundo familiar. Las mujeres casi no visitan a sus vecinas y platican más con las mujeres dentro de la propia familia. A pesar de esto afirma que aunque las mujeres están siempre bien informadas de lo que sucede en la comunidad, especialmente por sus hijos (Marion, 1999). El libro de Marion es el primer trabajo que se dedica especialmente a la situación de las mujeres. Marion ve varios aspectos de la vida cotidiana de las mujeres lacandonas conectada con lo que ella llama la cosmovisión ${ }^{4}$ (Marion, 1999).
Aunque no existen muchas referencias a la vida de las mujeres cuando los lacandones solían vivir en grupos familiares dispersos en la selva podemos ver en estas observaciones en distintos momentos que papel de la mujer era importante especialmente en el hogar y en la educación de los hijos. No poder conseguir mujer era de los problemas más grandes que enfrentaron los hombres; siempre trataron de conseguir mujeres para tener alguien que les preparara la comida y que les diera hijos (Marion, 1999).

El mundo de las mujeres era acotado al ambiente familiar y que sus contactos externos eran limitados. A pesar del cambio del tipo de asentamiento que ocurrió en la segunda mitad del siglo XX las mujeres seguían dedicándose a las tareas domésticas y sus actividades sociales continuaban dentro de las propias familias y muy poco en el ámbito comunitario. ¿Es posible que debido a la concentración en los pueblos permanentes y al desarrollo del turismo progresivo las mujeres ganaran una mejor posición en la sociedad lacandona y en las propias familias? ¿O gracias al consumo y mezcla de actividades domésticas con el turismo perdieron un poco el papel importante que ocupaban en las familias durante el tiempo cuando vivían en los grupos familiares, sin las tiendas, la venta de comida y sin fácil acceso a las ciudades cercanas? Seguramente las nuevas tecnologías les facilitaron muchas tareas en casa como preparar la comida, lavar y coser la ropa, ipero hasta qué punto influyeron en su conviviencia con la familia y en sus posibilidades de participar en las actividades comerciales?

Revisaremos con más detalle algunos aspectos de la vida de los lacandones y la participación de las mujeres con base en la literatura disponible. Como la mayor parte de la literatura habla de la religión, la organización familiar y los cambios en general escogemos los siguientes temas para analizar el papel de las mujeres: la organizacion familiar, las ceremonias, el vestido y sus características, y los contactos de la mujer lacandona con el mundo exterior. 


\subsection{El ámbito familiar}

Los Lacandones solían vivir en pequeños grupos familiares dispersos en la selva hasta la primera mitad del siglo XX. El matrimonio preferido era en poligamia; el hombre tenía derecho de tener más de una mujer. Las esposas solían vivir y trabajar juntas y por lo común fueron casadas cuando eran todavía pequeñas (Duby, 1961).

Tozzer refiere que los lacandones normalmente practicaban la poligamia pero que era muy raro ver que el hombre tuviera más de tres mujeres en la casa. Dice que por lo general las mujeres vivían juntas y compartían las tareas del hogar. Sin embargo, menciona que no tenían el mismo nivel de importancia dentro de la familia y que siempre existía una mujer preferida. Según sus observaciones se prefería a la primera esposa (Tozzer, 1982). Según mis informes de campo no era siempre el caso. Por ejemplo, en la familia de Chan Kin Viejo de Nahá la tercera esposa era la privilegiada, con ella siempre comía en la misma mesa y dormía en la misma cama. Las otras esposas comían en la compañía de sus propios hijos y dormían separadas.

Gertrude Duby también anota que la poligamia entre los lacandones era muy común y que a pesar de que existía una mujer preferida, no existían celos y eran capaces de vivir en armonía. La mujer mayor tomaba muy naturalmente la llegada a la casa de la mujer joven y ella le debía enseñar a hacer tortillas, atender el fuego y otras tareas domésticas. Según Duby la mujer por lo general quería tener otra compañera en casa y se quejaba si no la tenía. En la mayoría de las cocinas lacandonas había tantos fuegos como mujeres tenía el hombre (Blom, Duby, 2006). McGee dice que por lo común las mujeres en la misma casa se llevaban bien pero que también se detectaron algunos casos en que la mujer mayor atormentaba y le pegaba a la co-esposa menor. Por eso el hombre a menudo prefería tomar como segunda esposa a la hermana menor de la primera, para evitar los posibles conflictos (McGee, 1990). Aun así, los matrimonitos de tipo poliginia sororal eran más comunes en las comunidades del sur, donde valía la regla de matrilocalidad.

Marion agrega al respecto que a veces las mujeres querían abandonar a su marido si no conseguía una coesposa con quien pudiera repartir las tareas domésticas. Pero seguidamente afirma que no todas las esposas eran así y que se presentaron casos en que las mujeres se opusieron a la segunda esposa o a veces la hacían sufrir con malos tratos, provocando incluso la muerte de la co-esposa joven en algunos casos (Marion, 1999). Hay que mencionar que aunque las mujeres repartían la mayor parte de las tareas en casa, cada una de ellas daba preferencia a sus propios hijos. Warren R. DeBoer habla de la poliginia en Perú entre los Conibo y apunta que este tipo de matrimonio era favorecido ya que el trabajo de cada mujer tenía un gran valor. Las mujeres eran responsables de la produción agraria pero también de preparación de los alimentos y cerveza de mandioca (DeBoer, 1986). Aunque los autores por lo general hablan sobre la conviviencia en armonía se pueden ver también casos donde las mujeres no se aceptaban tan fácilmente y donde existía competencia por el estatus en la familia, tanto en conocimientos como en cosas materiales. La práctica de poliginia era común en muchas sociedades indígenas y varios autores hablan justamente sobre la competencia entre las co-esposas particulares.

Según mis datos de campo las mujeres no se peleaban tanto entre ellas por la preferencia del hombre sino por las cosas que recibían. Por ejemplo, si el hombre estaba casado con tres mujeres y se requería una sartén, tenía que comprar tres para evitar conflictos dentro de la familia. Sin embargo, algunas mujeres que vivían como co-esposas me platicaron que a veces sentían competencia y enojo entre ellas, lo que en ocasiones llegaba a situaciones en que las mujeres no preferidas trataron de buscar estrategias para poder lastimar a la mujer preferida. Kate Crehan habla de la poliginia en Zambia, África y apunta que era favorable para los hombres pero no tanto para las mujeres. Dice que 
implicaba competencia entre ellas sobre todo en el aspecto material y que era muy mal visto que el hombre no dividiera las cosas y el dinero igual entre todas sus mujeres (Crehan, 1997).

Los lacandones en el pasado tenían que enfretar muchos conflictos y tensiones por falta de las mujeres, lo que les forzaba a casarse con las de la propia familia o a robarlas de otros clanes familiares. A veces llegaron los hombres de una familia a matar los rivales de otros clanes para poder garantizar una mujer y evitar así la venganza (Marion, 1999). El hombre perdía el estatus si no lograba tener al menos una esposa. Por tanto, no pasaba que una mujer se quedara sola; en caso de que el esposo se muriera, la mujer era tomada por otro hombre de la familia. No importaba si el hombre era mucho más joven o si ya tenía esposas (Marion, 1999).

Jacques Soustelle menciona una familia lacandona en un caribal donde el padre tuvo dos mujeres, la madre y su hija, y los tres vivían en la misma casa. Además, se refiere a la edad de casamiento entre los jóvenes y dice que no era nada extraño ver a una niña de cinco años ya casada (Soustelle, 1934, en De Vos, 2003).

Philip Baer, quien era uno de los primeros misioneros quien llegó con el propósito de convertir la gente local al evangelismo, estuvo en los años 40 en Nahá y en los 60 se mudó a Lacanjá. Baer advierte sobre este tipo de convivencia y concluye: "hay varios casos de matrimonio entre hermanos completos o entre medio hermanos, y muchos con los hijos de hermanos" (Baer, Merrifiend, 1972: 31). Algunos hombres se casaron con sus suegras, otros con sus madrastras. También señala, sobre el grupo del sur, que por lo general las niñas de entre 6 y 8 años estaban ya casadas, comúnmente acompañaban a sus esposos a la selva y cuidaban la casa. Afirma que la sociedad lacandona no era tan ideal como varios autores la imaginaron y que uno de los problemas más graves en las comunidades era la falta de mujeres. Además de casamientos con los miembros femeninos de la misma familia donde no importaba la edad, Baer registró varios casos de raptos de las mujeres de los otros clanes familiares (Baer, Merrifield, 1972). Marion agrega que los lacandones vivían en estricta endogamia y que por eso a menudo enfrentaron el problema de la escasez de mujeres y la necesidad de los raptos. "Eso provocó inevitablemente una serie de represalias sangrientas, la huida de la familia agredida, el abandono provisional de las tierras de labor así como la búsqueda de una nueva tierra de cultivo" (Marion, 1999: 77); reporta que los hechos más sangrientos estaban siempre conectados con raptos de las mujeres. Según informes disponibles, parece que dicha práctica era más común entre los lacandones del sur pero, como ella misma menciona, no tenemos información suficiente sobre dichas prácticas en el grupo del norte (Marion, 1999).

La poligamia era muy común, especialmente cuando los lacandones todavía vivían en los caribales. Después, con la llegada de los primeros misioneros y con la fundación de los primeros templos protestantes se ha reducido este tipo de matrimonios

\subsection{Las ceremonias religiosas}

Uno de los temas principales en que se enfocaron las primeras etnografías fueron las ceremonias religiosas, sus reglas, significados y realización. Como en muchas culturas indígenas la participación y adminitración correspondía a los hombres, quienes gracias a sus oraciones y ofrendas podían comunicarse con los dioses.

Las mujeres no particaban activamente y su tarea principal era la preparación de la comida sagrada que después los hombres usaban como ofrenda. Tozzer apunta que las mujeres no tenían permitido participar en las ceremonias religiosas y que podían estar solamente en la cocina anexa a la casa de Dios y preparar los alimentos para las ofrendas a los dioses. De esta tarea no se encargaban todas las mujeres sino solamente la mujer preferida del hombre, quien por lo general tenía más experiencia que las otras (Tozzer, 1982). Jacques Soustelle, en los años treinta, igualmente observó las reglas ceremoniales y dijo que estaba prohibido para 
todas las mujeres de la familia entrar a la casa de Dios y que solamente las mujeres mayores tenían derecho a preparar alimentos sagrados para los dioses. Menciona que los hombres cuyas esposas no sabían preparar ofrendas tenían en la familia una posición subordinada en relación con otros hombres (Soustelle, 1934, en de Vos, 2003). McGee indica que por lo general a las mujeres no se les permitía participar activamente en los rituales religiosos excepto en la ceremonia de hetzmek, el ritual durante cual los niños deberían prepararse para su papel venidero de hombre o de mujer, es decir, un rito de paso. En el caso del nacimiento de una hija era necesaria la presencia de la mujer; en el caso de un hijo, participaba solamente el hombre (McGee, 1990).

Aunque las mujeres lacandonas no eran mediadoras directas de lo sagrado, no realizaban las ceremonias, tampoco se encontraban solamente en la esfera profana. Su papel durante la preparación de la comida sagrada era imprescindible componente de las ceremonias.

\subsection{Apariencia y vestido}

El primero que describe brevemente el vestido de las mujeres lacandonas en el área de Pethá fue Teobert Maler (a fines del siglo XIX) y dice: "las mujeres usan una falda que les cubre las pantorrillas y encima de ésta un camisón. Todas las mujeres se adornan con un racimo de collares. Las mujeres separan su cabello por la mitad y juntan los extremos de las trenzas con un manojo de coloridas plumas de pájaro. Todas las mujeres tienen perforados los lóbulos de las orejas. Ni ellas ni los hombres parecían usar calzado de ningún tipo" (Maler, 1898, en de Vos, 2003: 153). Tozzer menciona, acerca del vestido, que las mujeres usaban el mismo poncho que los hombres, además de una falda sencilla que llega hasta las rodillas. El cabello lo traían atado, con una trenza que adornaban con una cantidad de plumas de pechuga de pájaro (Tozzer, 1982). Según Duby las plumas en el pelo de la mujer significaban que ya estaba casada (Duby, Blom, 1969). Aunque el vestido de las mujeres del sur y del norte era diferente los hombres usaban la túnica blanca. Sin embargo, también existían pequeñas diferencias en la longitud dependiendo de la localidad (Boremanse, 1998).

Didier Boremanse distingue el vestido de las mujeres del norte y las del sur. A diferencia de las mujeres del norte que usaban la falda y la blusa, las mujeres del sur se vestían de túnica igual que los hombres. Dejaban el cabello suelto y no usaban trenza como las mujeres del norte. Boremanse reporta que las jóvenes mujeres de Nahá empezaron poco a poco a vestirse con ropa occidental; las de Lacanjá siguían usando la túnica (Boremanse, 1998).

\subsection{Los contactos con gente foránea}

El tema de las relaciones externas de las mujeres igual que sus contactos es bastante complejo y requiere ver más el contexto de los problemas y beneficios que experimentaron los lacandones en el pasado, cuáles factores provocaron los cambios y por qué razón se distiguen de los otros grupos indígenas en Chiapas.

Los encuentros de las mujeres con los foráneos eran limitados, ya que los contactos principales con los primeros explotadores de maderas preciosas, los investigadores, los antropólogos y los chicleros, eran siempre manejados por los hombres. Ellos buscaban los lugares para negociar e intercambiar sus productos. También los antropólogos e investigadores trataban siempre con los hombres. No registré ninguna referencia de la primera mitad del siglo XX que mencionara alguna mujer negociando o tratando con las personas fuera de su caribal. Marion menciona que las mujeres lacandonas siempre preferían quedarse atrás porque los extranjeros les daban miedo tanto por las enfermedades que traían como por la violencia que a veces usaban (Marion, 1999).

Más bien, las mujeres no eran quienes negociaban sino, a veces, el motivo del negocio. Según mis informes de campo esto sucedió sobre todo durante la época de los chicleros, en los años de 1940-1945. Según los datos 
obtenidos, los hombres a veces cambiaban sus mujeres por objetos como machetes, rifles u otras cosas que le facilitaba la vida cotidiana. Las mujeres así conocieron mucha violencia tanto de parte de los chicleros como de sus propios maridos. Nakin dice:

Cuando mi padre llegó a Lacanjá, me vio muy crecido. Dijo que era tiempo de buscarme un marido... Mellevó con los chicleros. No llevaba más que mi cotón, ni zapatos tenía yo entonces. Creo que por eso mi papá mellevó con los trabajadores de El Cedro. Me cambio por un par de sabuesos, grandes los sabuesos, bonitos que eran. (Marion, 1999: 23-24).

En Lacanjá actualmente registré un caso de una mujer cuyo padre no es el marido de su madre, sino un chiclero.

Un cambio notable que afectó bastante la vida de las mujeres, de los lacandones en general, fue la invasión de los campesinos de la región de Los Altos de Chiapas hacia La Selva. La incursión de los tzeltales, tzotziles y choles empezó en los años 40 y cada año se intensificaba más, agregando a otros agentes externos con quienes comenzaron a tratar. Al mismo tiempo, los lacandones acostumbrados a vivir en clanes particulares tuvieron que juntarse poco a poco en comunidades permanentes que fueron fundadas a partir de 1940: Lacanjá Chansayab, Nahá y Metzabok. Las mujeres, que vivían siempre aisladas dentro de una familia sin contacto con la gente de alrededor, se encontraron de repente rodeadas por otras personas.

La concentración parcial de los lacandones en los pueblos permanentes facilitó también el esfuerzo de los misioneros quienes empezaron a establecerse en las comunidades y fundaron los primeros templos protestantes. Los templos poco a poco se volvieron en el centro social para distintas familias. Como ya mencioné, Felipe Baer era uno de los primeros misioneros que llegó a principios de los años 40 a Nahá, buscando establecer una nueva religión; por no tener mucho éxito en las comunidades del norte se decidió a cambiar en los años 70 a Lacanjá Chansayab, en el sur. Hay que agregar que Felipe junto con la nueva religión trajo también medicamentos y vacunas para la gente, pues en estos años la gente sufría mucho por varias enfermedades de fuera, como el sarampión y la viruela. Muchos indígenas en esta época especiamente en las comunidades del sur poco a poco abandonaron su religión por no poder ayudar con los rituales a los niños, mujeres, hombres que se morían mucho por las enfermedades. El templo que construyó Felipe se volvió para la gente un lugar de confianza y protección (Marion, 1999). Especialmente las mujeres empezaron participar activamente durante las ceremonias, ya que reglas como la prohibición del alcohol y de matrimonios poligámicos les ayudaron a evitar un poco la violencia familiar causada sobre todo por el consumo excesivo del alcohol. Dice Chanes:

Fuerte era su palabra de Felipe, porque él era derecho y sabía cómo hablar con mis companeros. Entonces ellos lo escuchaban y escuchaban la palabra de Dios. Ya no pegaban tanto como antes, ya no se enojaban tanto. Por eso me gustaba ir al templo, porque de esa manera yo sabía qué cosa era bueno o malo hacer (Marion, 1999: 84).

En los años 70, otro cambio importante fue la creación de la Zona Lacandona por parte del gobierno. Debido a la deforestación extrema, el gobierno decidió otorgar 614 mil hectáreas de tierra a los lacandones (exactamente a los 66 jefes de familia), "a los últimos mayas auténticos”, que estaban muy acostumbrados a convivir con la selva y a cuidar de ella. Sin embargo, como ya se mencionó, el gobierno puso una condición para otorgar la tierra: que todos los lacandones que todavía vivían dispersos en la selva se concentraran a vivir en los pueblos permanentemente. En el año 1975 se extendió esta zona a 662 mil hectáreas para que incluyera también a los pueblos del norte, Nahá y Metzabok. Con el decreto de la Zona Lacandona, los lacandones se convirtieron en los más grandes propietarios de tierra en la historia 
moderna de México. Como menciona Boremanse, en el año de 1974 los lacandones hicieron un contrato para la extracción de cedro y caoba de su territorio y así recibieron dinero de Nacional Financiera: "70\% de estos fondos fue administrado por el Fondo Nacional de Fomento Ejidal (FONAFE), para subsidiar diversos proyectos de desarrollo, y el 30\% restante fue distribuido entre jefes de familia". Hay que mencionar que la tierra y los derechos correspondientes siempre se entregaban a los jefes de familia, que eran hombres. No registré ninguna mujer lacandona con derechos de la tierra excepto a las viudas, quienes obtuvieron el derecho después de la muerte de sus esposos (Boremanse, 2006).

Todos estos cambios (la presencia de los otros grupos étnicos, el asentamiento en pueblos, así como el reparto de la tierra), modificaron el modo de la vida de los lacandones, tanto en lo familiar como en lo económico. A partir de los años 70 las mujeres lacandonas, al igual que los hombres, empezaron a casarse con miembros de otros grupos indígenas de alrededor; las mujeres jóvenes, particularmente, empezaron a vestirse con ropa de estilo occidental y poco a poco comenzaron a amueblar sus hogares con cosas nuevas (Boremanse, 1998). Los jóvenes cambiaron su actitud hacía las normas de conviviencia y empezaron rechazar el modo original de selección de la esposa: "El poder de los mayores llegó a ser cuestionado, así como las obligaciones de servicio nupcial que habían sido uno de los principales sostenes del sistema social en su conjunto" (Marion, 1999: 113). La llegada de las mujeres no lacandonas también hizo la situacion más difícil para las mujeres locales. Las mujeres viudas en el pasado siempre eran retomadas de algún hombre inmediatamente después de la muerte de sus maridos (Marion, 1999). Actualmente, con tanta opción de conseguir mujeres de otros lados, las viudas se quedan por lo general solas y tienen que buscar la manera como sobrevivir.

Con base en la creación de la zona lacandona y la imagen de sus propietarios como los últimos mayas auténticos, empezaron a penetrar en el área las agencias de viajes, las organizaciones gubernamentales y no-gubernamentales y se comenzaron a fundar los primeros centros ecoturísticos. En comparación con los otros campesinos de alrededor, en las comunidades lacandonas muchos proyectos se enfocan en el turismo y se invierte mucho más dinero en el desarrollo de centros turísticos y elaboración de artesanías, aunque también hay cursos de salud y medioambiante.

En los años 80 en Lacanjá fueron fundados los primeros campamentos turísticos y a partir de esta época empezó poco a poco a desarrollarse esta actividad. Hay que mencionar que Lacanjá, en comparación con Nahá, tiene siempre ciertas ventajas: mejor carretera y la cercanía a las ruinas de Bonampak y Yaxchilán. Los hombres campesinos de cada familia se convirtieron en los dueños de las cabañas, de los restaurantes y en los guías de turistas. Sin embargo, dichos negocios también tienen un carácter más masculino, puesto que no está registrada ninguna mujer lacandona como dueña de algún campamento. Las mujeres por lo general ayudan con la limpieza o con la preparación de la comida, pero el contacto principal con el cliente y el dinero siempre está a cargo del hombre. Esto es diferente de las mujeres no lacandonas, especialmente tzeltales o tzotziles, quienes en el caso de Lacanjá abrieron algunos restaurantes o taquerías donde manejan su propio dinero; en cambio, las mujeres locales por lo general no estan involucradas en estos tipos de negocio.

Igual que en las cuestiones religiosas, en las familiares y en las relaciones con el mundo externo se refleja el tema del poder y de las tensiones que experiementaban tanto mujeres lacandonas como los hombres. De una parte los lacandones sufrían mucho por varias enfermedades, muchas mujeres por las violaciones y agresión, y por perder su asentamiento tradicional. Por otra parte, por ser tan "singulares" y "exóticos" se les dieron muchos beneficios, en comparación con otros grupos indígenas en Chiapas.

En resumen, las etnografías nos ofrecen algunas imágenes acerca de la vida, la posición y carácter de la 
mujer lacandona. Según las descripciones parece que la mujer tenía un papel importante dentro de la familia, especialmente en el hogar y en la educación de los hijos. Las primeras etnografías mencionan también la fuerza de la mujer, que se mostraba en el trabajo agrícola y en las tareas domésticas. Los lacandones solían practicar poligamia, por eso en las familias particulares por lo general convivían más mujeres y entre ellas dividían el trabajo cotidiano. Aunque el papel de la mujer era importante en el ámbito familiar es visible que su participación fuera del hogar era limitada por los miembros masculinos de cada familia. Las mujeres no podían participar activamente durante las ceremonias religiosas ni colaboraban mucho en la vida social. El cambio de tipo de asentamiento, la cercanía de los nuevos vecinos y poder obtener el dinero por reparto de las tierras seguramente influyeron en el modo de la vida de los lacandones. ¿En qué forma se modificó el estatus de la mujer en la sociedad lacandona y en las propias familias? La concentración de los lacandones en las comunidades permanentes causó muchos cambios en la vida cotidiana, en la manera de subsistencia ipero también en la vida social y familiar?. Los lacandones se volvieron más accesibles a los misioneros, antropólogos, agencias de viajes y turistas. Igual que los hombres, las mujeres empezaron poco a poco sustituir sus actividades agrícolas y domésticas por las comerciales, modificando a su vez algunas costumbres y reglas dentro de la sociedad pero también dentro de las familias, como se analiza en las siguientes páginas.

\section{Las mujeres lacandonas en la sociedad contemporánea}

Se ha analizado aquí la forma de organización familiar, la manera de subsistencia, actividades diarias y los cambios importantes en la cultura lacandona presentada por las etnografías del siglo XX. La siguiente parte está basada en el trabajo de campo realizado en dos pueblos lacandones contemporáneos, Lacanjá y Nahá, durante los años 2008 y 2009. El propósito es analizar cómo los cambios esenciales han afectado la vida de las mujeres lacandonas en la familia y también en la comunidad en general. Vamos a ver cómo ha cambiado la vida de las mujeres a través de tres generaciones principales: las mujeres mayores, las adultas y las jóvenes. Me enfoco, sobre todo, en la participación de las mujeres en la vida social, en sus actividades laborales y en su posición en la vida familiar.

No se puede hablar de la vida y de la posición de la mujer lacandona en una forma homogénea ni se puede decir simplemente que la diferencia principal está vinculada al origen de la mujer, si es del sur, de Lacanjá, o del norte, de Nahá, aunque desde un punto de vista la vida de ellas puede ser distinta dependiendo de este factor. Por ejemplo, se podría decir que las mujeres de Lacanjá participan más en las actividades turísticas que las de Nahá; sin embargo, éstas también elaboran artesanías aunque no en tanta cantidad como las de Lacanjá. Las mujeres de los dos pueblos viven en condiciones diferentes pero también tienen mucho en común: les gusta vestirse bien, comprar cosas, mirar las telenovelas, atender a sus niños y estar con sus familias. Tampoco se puede hablar de las mujeres lacandonas de manera aislada sino en la relación con la familia. En la vida de ellas, las costumbres y reglas están siempre vinculadas a la conviviencia con los padres, los hermanos, los esposos y luego con los hijos. Las condiciones de la convivencia en cada familia reflejan en cierto modo el estatus que la mujer tiene dentro de ella y en la sociedad en general.

Escalona menciona que las reglas y condiciones dentro de las familias no son iguales y que siempre surgen de una serie de conflictos y tensiones:

La organizacion de la familia y su trayectoria no son sólo resultado simple de la reprodución de las distinciones establecidas. El proceso de formar una casa revela las contradicciones y la competencia 
regulares implicadas en esta socialidad particular (Escalona, 2009: 239).

Según Escalona, en su estudio sobre los tojolabales, es el poder, por lo general de la autoridad masculina, el que se refleja en las diversas formas de la conviviencia en las familias mismas. "Las diferencias del poder producen un dominio basado en relaciones cooperativas y conflictivas al mismo tiempo" (Escalona, 2009: 238).

Igualmente, Marion menciona el poder de las autoridades masculinas pero también plantea diferentes estrategias de las mujeres en el hogar cuando tratan de lograr algunos acuerdos (Marion, 1999). Chan Kin Viejo era una de las autoridades más fuertes en la comunidad Nahá. Él ponía condiciones que seguía toda su familia. En este caso hay que mencionar que la cuestion del poder no se reflejaba solamente en el asunto de género, entre él y sus mujeres, sino también en la relación con sus hijos y yernos. Aunque sus hijos casados y sus yernos eran jefes de sus propias familias, su situación frente a Chan Kin Viejo seguía siendo subordinada. De este ejemplo se ve claramente que el poder no es solamente cuestión de género, sino que se refleja también en la relación del hombre y sus yernos, igual que entre las mujeres en el hogar, entre la nuera y la suegra.

Entre las familias particulares hay diferencias importantes, tanto en el nivel de la vida de las mujeres como en sus trabajos cotidianos, en las posibilidades de escoger marido, en las oportunidades de recibir dinero, estudiar, planificar la familia, poder tomar decisiones y participar en la vida social. Hay familias en las que las mujeres mismas pueden escoger a su marido según sus gustos, pero también hay todavía familias donde sólo el padre tiene la palabra en la elección del marido. Hay mujeres que participan activamente en el turismo, así como hay mujeres que sólo se dedican a sus tareas domésticas.

En general, el turismo y los medios de comunicación han influido en las familias. Los cambios más generales, más visibles y más rapidos son los que se conectan con la comercialización, el consumo y las actividades turísticas; mientras, los cambios en el ámbito familiar y social son más lentos y más variados de una familia a otra.

\subsection{Las actividades de las mujeres en la vida social}

La vida y la posición de las mujeres lacandonas ha cambiado mucho en los últimos treinta años a causa del turismo, la evangelización, la propiedad de las tierras, ${ }^{5}$ la modernización y las nuevas tecnologías. Sin embargo, a pesar de estos cambios la vida social de ellas, su participación en la escena política, sus derechos de tomar decisiones en las familias y sus oportunidades de trabajo asalariado están hasta ahora bastante limitadas por los hombres. Como en muchas comunidades rurales el hombre es considerado como el jefe de familia, la autoridad, el que toma las decisiones más importantes, que representa a la familia en público y a quien deberían obedecer los demás. A pesar de que algunas mujeres entraron al mercado laborar y pueden ganar algo de dinero su estatus en las familias no cambió radicalmente. Fiona Wilson quien hizo investigación entre las mujeres en Tangamandapio, Michoacán, anota que el cambio más notable en la vida de las mujeres era el poder ganar y controlar su propio dinero. En caso de las mujeres lacandonas son más visibles los cambios en las cosas materiales, por ejemplo la mujer que gana dinero puede comprarse más ropa, pero su vida social y familiar sigue limitada por el esposo, el padre o el hermano. Sin embargo, ese cambio tal vez va a ser la cuestión de otra generación, porque Wilson misma menciona que la primera generación de mujeres que entró al mercado laboral, entregaba su salario al marido y seguía la misma vida familiar que antes (Wilson, 1990).

En las comunidades lacandonas las mujeres solas no pueden salir de casa sin pedir permiso a sus esposos y después depende de ellos si las dejan ir o prefieren 
acompañarlas. Según mis observaciones en la mayoría de los casos la mujer va siempre acompañada de algún hombre de la familia. Creo que es interesante poner aquí un ejemplo de una estudiante lacandona que está en la universidad en San Cristóbal. En el caso de ella se ve muy claramente cómo cambia sus costumbres y formas del comportamiento cuando está en la ciudad y cuando regresa a su comunidad. En la ciudad sale sola, está con sus amigos, pero en cuanto regresa a su casa retoma de nuevo reglas de la familia: no sale sin pedir permiso o sin la compañía de algún hombre del hogar. Esto no es solamente cuestión de respetar la autoridad y seguir las reglas, también juegan un importante papel los chismes, que son algo muy común en las pequeñas comunidades.

Igual que en la vida social, la participación en las reuniones comunitarias y las elecciones de sus representantes está dirigida principalmente por los hombres. En primer lugar las mujeres casadas no tienen derecho a votar para elegir a los representantes de la comunidad y segundo, muchas de ellas dicen que no tienen interés en participar. La excepción son las viudas quienes obtuvieron derecho para votar después de la muerte de sus maridos. En caso de que la mujer casada esté interesada de verdad en las cuestiones políticas comunitarias puede acompañar a su marido, aunque activamente no le corresponde tomar decisiones. Según lo que observé participan más en estas juntas las mujeres jóvenes de Lacanjá que las de Nahá.

Elúnico lugar donde participan más activamente las mujeres que los hombres son los templos evangélicos. A la mayoría de las mujeres les gusta participar en las ceremonias y vienen al templo muy seguido. No es nada extraño que una parte de la familia sea bautista pero la otra cuya vivienda está más cerca del otro templo sea, por ejemplo, pentecostés. Se puede decir que "ir al templo" es para las mujeres una de las pocas oportunidades para juntarse y platicar. Sin embargo, en caso de la generación de los adolescentes ya se ve menos interés en las cuestionas religiosas.
La posición de las mujeres y su participación en el ámbito familiar y comunal refleja los importantes cambios que han ocurrido en la sociedad lacandona desde la mitad del siglo XX. Sin embargo, mediante el análisis de tres generaciones distinas de mujeres se puede observar cuáles de los cambios provocaron los impactos esenciales en la vida local y hasta qué punto modificaron de manera muy variada el comportamiento de dichas mujeres dentro de las familias y también dentro de la comunidad en general. El modo de vida, las costumbres, las tareas diarias, las expectativas, los sueños y el comportamiento mismo están en cierta medida relacionados con la edad de las mujeres. Según la edad, se podrían distinguir tres generaciones principales: las señoras mayores de más de 45 años, las mujeres adultas entre 26-45 años y las jóvenes entre 15-25. Hay que mencionar que es necesario dividir los grupos así ya que las mujeres de 15 años están a menudo casadas y tienen hijos.

\subsubsection{Las mujeres mayores}

Las mujeres mayores por lo general están más acostumbradas trabajar en casa, la mayoría de ellas no habla español, ninguna de ellas recibió educación escolar y hoy son casi las únicas que siguen vistiéndose con la ropa típica de los lacandones. En el caso de Lacanjá es una túnica larga; en Nahá una blusa blanca y la falda de colores. Dichas mujeres todavía crecieron en los clanes dispersos donde sus contactos eran limitados al ámbito familiar. Era el hombre el que negociaba con los chicleros, antropólogos, exploradores y visitantes.

Lo que aprendían esas mujeres era a preparar comida, trabajar en casa, cuidar a los niños y atender a sus esposos. Todas las mujeres mayores acuerdan muy bien la cantidad de trabajo que tenían que hacer todos los días cuando todavía no existían oportunidades de comprar cosas en la tienda, cuando todavía tenían que coser la ropa y cuando tenían que acompañar a sus 
esposos a trabajar duro en la milpa. Aunque el trabajo en la milpa era sobre todo asunto de los hombres, las mujeres especialmente de las comunidades del norte de Nahá a menudo les asistían. Hasta hoy se puede fácilmente observar que las señoras grandes no descansan y todo el tiempo están dentro de sus casas haciendo algo.

Koh de Nahá (aproximadamente de 47 años) dice que solía trabajar mucho en casa. Cada mañana tenía que levantarse a las cinco; con sus co-esposas empezaba a moler maíz y a preparar las tortillas frescas. La preparación tenía que estar lista a la hora que se despertaba Chan Kin, su esposo. Algunos días le tocaba acompañar a su esposo a trabajar en la milpa, otros días se quedaba en casa lavando ropa, preparando comida, alimentando a los pollos, cuidando a los niños. Por la tarde otra vez molía maíz y preparaba tortillas frescas ya que Chan Kin rechazaba comer tortillas recalentadas. Así pasaba todos los días trabajando en casa. Sabía que en caso de no hacer todo que debía, Chan Kin la podría castigar.

Actualmentedichas mujeres poco a poco aprendieron a hacer artesanías y de cierta forma colaboran en las actividades turísticas, pero no las prefieren a sus tareas domésticas. Su participación en el turismo es más pasiva en comparación con las mujeres adultas y jóvenes; por ejemplo, elaboran artesanías, pero no las saben vender. Esto es más común en Nahá donde no se ha desarrollado tanto el turismo y donde las mujeres no están tan acostumbradas a estar en contacto con personas que no pertenecen a sus familias.

María Koh de Nahá (aproximadamente de 60 años) se dedica a veces a la elaboración de artesanías, produce objetos de barro, bolsas de la corteza, collares, pero cuando llegan los turistas y no saben que ella elabora dichas artesanías, no les muestra nada porque piensa que no les interesan. Tampoco está segura qué precio puede poner a su trabajo. Aparte de artesanías María Koh con su co-esposa Koh de vez en cuando reciben visitantes (muchos de ellos antropólogos), les rentan una cabaña y les venden comida. Sin embargo todavía no es negocio el ecoturismo, como en Lacanjá.

En Lacanjá ya aparecen algunas señoras mayores que saben hablar un poco de español y participan más en las actividades turísticas; por lo general elaboran y venden artesanías y pocas de ellas han empezado a trabajar también como guías. En este caso se trata más de las viudas que necesitan obtener algo de dinero para poder mantenerse, pero no exclusivamente.

Chana de Lacanjá (aproximadamente de 52 años) aprendió a hablar español cuando su hija estaba muy enferma y la tuvo que llevar a un hospital en el DF. Dice que al principio no entendía nada de lo que la gente le decía pero poco a poco era capaz de conectar algunas palabras y empezó a entender. La hija se murió y Chana se regresó a Lacanjá. Ahora se dedica a elaboración de artesanías y también de vez en cuando lleva a los turistas a ver las cascadas de Lacanjá.

Nakin de Lacanjá (aproximadamente de 50 años) no tiene marido, por lo que tiene que mantenerse sola. Nakin aprendió a hablar español con los turistas, también se dedica a la elaboración de artesanías y a veces trabaja como guía en la selva. Nakin aprendió a comerciar muy bien. Así, compra artesanías de las otras mujeres a un precio más barato y después las revende más caras en el campamento de su hermano.

En el caso de las mujeres mayores podemos ver que los cambios hacia la vida comercial afectaron especialmente a las mujeres viudas o solteras, quienes tuvieron que buscar la manera de mantenerse y conseguir algo de dinero. Estas mujeres aprendieron un poco de español y empezaron tener un papel activo en el turismo. En las familias de esa generación es más evidente que el hombre se dedica más a las actividades turísticas que la mujer y por lo general las actividades comerciales se combinan con el trabajo en la milpa. Las mujeres mayores estaban acostumbradas a la vida en los caribales particulares donde sus contactos eran limitados al ámbito familiar. 


\subsubsection{Las mujeres adultas}

Las mujeres adultas (entre 25-45) cuando eran niñas, vivían todavía en condiciones parecidas a sus mamás. Sin embargo, la mayoría de ellas creció ya en los pueblos permanentes; entonces, en comparación con sus mamás, estuvieron desde niñas más acostumbradas a convivir con gente de alrededor. Casi ninguna tuvo educación escolar y las que acudían a las clases por lo general lo hacían sólo por 2 o 3 años y solamente en Lacanjá. Como en Nahá en este tiempo no había escuela, las mujeres de esta generación no saben leer ni escribir. Las mujeres adultas demuestran mucho más interés en las actividades turísticas si las comparamos con las mayores. A menudo prefieren este tipo de trabajo por el cual obtienen algo de dinero, a diferencia del trabajo en casa. La mayoría de esas mujeres elabora artesanías y las vende directamente en el pueblo de Lacanjá o cerca de las ruinas de Bonampak; en Nahá; por lo general son los hombres quienes salen a venderlas a las ciudades cercanas como Palenque, Ocosingo o San Cristóbal. Tomando en cuenta las posibilidades de vender, es muy probable que las mujeres de Lacanjá puedan obtener más dinero a causa del contacto directo con el cliente, comparadas con las mujeres de Nahá en donde el mediador es el esposo.

Las mujeres de Lacanjá dentro de las actividades turísticas se dedican también a la limpieza de campamentos o a la preparación de la comida para vender. El dinero de las cabañas y de la comida lo recibe el hombre pero después, tomando en cuenta el trabajo de cada quien, divide una parte entre las mujeres que participan. Como a Nahá no llegan tantos turistas se ve muy rara vez que las mujeres trabajen en las cabañas. Como menciona Doña Betty ${ }^{6}$ a veces ofrezco a las mujeres que vengan a ayudarme a prepar comida para los turistas, pero ellas no quieren, les da pena o no les permiten sus maridos.

Hay algunas mujeres adultas de Lacanjá quienes intentaron trabajar con los turistas directamente como guías y los llevaban solas a la selva. En el pueblo la gente no respetó este esfuerzo y empezó hablar mal de ellas, por lo que las mujeres no intentaron incorporarse en este tipo del trabajo de nuevo.

Koh (35 años) de Lacanjá dice que le gustaba estar en contacto con la gente y llevarla hasta las ruinas de Lacanjá o hasta las cascadas. Después los vecinos empezaron a decir que vendía su cuerpo, pues no es aceptable que la mujer vaya sola con otras personas que ni conoce.

De este ejemplo podemos ver muy claramente que este tipo de actividades laborales se respeta solamente en caso que la mujer no tenga esposo y tenga que mantenerse sola. Sin embargo, si la mujer tiene esposo no se le permite este tipo de labores. En las comunidades lacandonas se supone que principalmente el hombre debería ser quien trabaja, trata con la gente y recibe dinero. En este ejemplo se refleja claramente el poder de la autoridad masculina, pero también papel del chisme en cada comunidad.

De ambos pueblos registré solamente una mujer adulta quien tuvo por algún tiempo trabajo asalariado. Sin embargo, hay que mencionar que por falta de educación suficiente, perdió el trabajo y no volvió a recibir otra oportunidad.

Koh (38 años) de Lacanjá años obtuvo la oferta de trabajar con los niños pequeños en la guardería cuando tenía 20. Como ella tuvo la posibilidad de estudiar la primaria, aunque solamente 2 años, enseñaba a los niños lo que ella misma sabía: el alfabeto y a contar, básicamente. Le gustó trabajar, participar en las reuniones en Tuxtla y recibir su salario. Cuando le pregunté qué había hecho con su primer salario, sonrió y contestó que todo lo había gastado en ropa y maquillajes.

En comparación con las mujeres mayores, las mujeres adultas ponen mucho más importancia a la educación de sus hijos porque saben que es casi imposible conseguir un trabajo y ganar dinero sin saber al menos lo básico, leer y escribir, aunque la mayoría de ellas no recibió educacion escolar. Varias de ellas se 
preocupan por el futuro de sus hijos, no quieren que se casen tan jóvenes como ellas y están intentando ahorrar un poco de dinero para poder apoyarlos en sus estudios.

En caso de las mujeres adultas se puede observar un cambio más visible hacia las actividades turísticas si lo comparamos con las mujeres mayores. En la vida de dichas mujeres influyó sobre todo el desarrollo del turismo y poder de recibir el dinero, pero también la formación de las instituciones nuevas como la clínica, la escuela y los templos protestantes. Debido a esas instituciones se ha reducido la natalidad, se ha mejorado la salud de las familias, se extendió la educación y se ha reducido la presencia de la poligamia. Sin embargo, estos cambios influyeron más rápidamente a las mujeres en Lacanjá donde las instituciones se establecieron antes y donde se desarrolló más el turismo, debido a la mejor carretera y a la cercanía de las ruinas mayas de Bonampak. A diferencia de las mujeres mayores, las adultas crecieron ya en los pueblos permanentes y estaban más acostumbradas de la cercanía de la gente, de los vecinos, vendedores, antropólogos, visitantes. En las familias de dicha generación por lo común trabajan en las actividades turísticas tanto el hombre como la mujer aunque por lo general es el hombre quien se encarga más de recibir visitantes y manejar el dinero. La mujer está más concentrada en la elaboración de artesanías que en el contacto directo con los visitantes. Igual sucede en el mercado laboral donde tienen más probabilidades de recibir el trabajo asalariado los hombres que las mujeres. Los cambios más visibles están conectados con el turismo, con la producción mercantil y con la educación, en comparación con la situación de la mujer en la familia en la comunidad, donde los cambios se producen más lentamente. Por ejemplo, aunque la mujer recibe dinero por vender las artesanías que elaboró tiene que pedir permiso a su marido para que la deje ir a comprar. Aun así la situación de las mujeres adultas ha cambiado bastante si la comparamos con las mujeres mayores; a pesar de que su vida está limitada por el hombre podemos ver más interés en la comercialización, el dinero y el consumo.

\subsubsection{Las mujeres jóvenes}

Las jóvenes no dedican mucho tiempo al trabajo en casa. La mayoría de ellas en Lacanjá compra tortillas hechas a máquina cada semana a los vendedores que vienen a la comunidad; las de Nahá usan regularmente Maseca (harina de maíz) y prensa para producir tortillas (en lugar de hacerlas con las manos). Según mi observación se ve muy rara vez que las jóvenes muelan maíz. Como ya casi nadie en ambas comunidades cultiva milpa, especialmente entre la generación joven, la mayor parte de la comida consiste en frijoles, tomates, chile o atún de lata. Cuando crecieron dichas mujeres, ya en las dos comunidades existía la escuela primaria; sin embargo, no todas asistían a las clases, especialmente en el caso de Nahá. En Lacanjá casi todas las jóvenes terminaron la primaria pero muy pocas de ellas siguieron la secundaria. En Nahá no en todas las familias le dieron importancia a la educación escolar para las mujeres y hay varias de ellas en la edad entre 19 y 25 que no saben leer ni escribir porque sus papás no les permitían asistir a las clases.

Nakin de Lacanjá (18 años), se casó cuando tenía 14 años pero ya no quería aprender a hacer tortillas, trabajar en la milpa y preparar comida. Le gusta estar en casa, mirar la televisión y acompañar a su esposo en los viajes fuera de la comunidad. Nakin terminó la escuela primaria pero después se casó y ya no le interesaba seguir con los estudios. A veces elabora artesanías pero no se esfuerza tanto como la mayoría de las mujeres adultas.

Chah Nuk de Nahá (22 años), se casó cuando tenía 18 años, que es en las comunidades lacandonas ya bastante tarde. Ella todavía creció en condiciones en que tuvo que aprender a hacer tortillas a mano, trabajar en la milpa, preparar comida y cuidar a sus hermanos menores. Actualmente también aprendió a usar Maseca, prensa 
y a cocinar las cosas de lata. Aunque Chah Nuk tiene su propia cocina, no le gusta estar allá sola y siempre prefiere cocinar junto con sus mamás. Chah Nuk no obtuvo educación escolar alguna porque sus padres no daban importancia a los estudios de las mujeres en casa. Chah Nuk se dedica junto con su esposo a la elaboración de flechas de artesanía que después los dos van a vender en San Cristóbal y Ocosingo.

En el aspecto laboral las mujeres jóvenes realizan también artesanías pero según mi observación no en tanta cantidad como las mujeres adultas. Algunas de ellas en Lacanjá se dedican a la preparación de la comida para los turistas, trabajan en las tiendas o se quedan en casa ayudando a sus mamás. Actualmente hay dos casos de mujeres, también de Lacanjá, quienes por su cuenta se fueron a buscar trabajo asalariado. En Nahá la mayor parte de las jóvenes están en casa ayudando con las tareas domésticas. Hay que mencionar que también en Nahá hay mujeres que preparan y venden comida; sin embargo, son pocas y no lo hacen para los turistas sino para la gente local durante la entrega del dinero del programa Oportunidades del gobierno federal o en ocasiones en que el pueblo se llena y ellas tienen la posibilidad para vender. Registré cuatro mujeres en Nahá que tratan de conseguir dinero de esa manera, dos de ellas son madres solteras.

Prisma de Lacanjá (19 años) terminó su primaria pero como no hay escuela secundaria en la comunidad no siguió con sus estudios. El año pasado se quedó en casa y ayudaba a su mamá a elaborar artesanías. Durante un año aprendió, por su cuenta, a usar la computadora y buscó trabajo fuera de su familia. Aprendió a cocinar e ingresó a trabajar en una cocina en otro campamento donde puede regularmente recibir algo de dinero. Durante un año ha cambiado mucho su visión de la vida, dejó de estar en casa aburriéndose y se fue a buscar nuevas cosas para aprender.

Adriana de Nahá (22 años) es un caso excepcional ya que de ambos pueblos es la única chica lacandona estudiando en la universidad. Dice que sus papás siempre la apoyaron, como a sus hermanos, en los estudios; ellos explicaban que es importante aprender para conseguir después el mejor trabajo. Después de terminar la escuela primaria tuvo que acostumbrarse a estudiar fuera de la comunidad. Ahora está estudiando en la universidad en San Cristóbal y poco a poco se está acostumbrando a la vida en la ciudad.

Como podemos ver las jóvenes prefieren las actividades comerciales que les permiten recibir dinero a las tareas domésticas. Aunque cosas básicas como preparar la comida o lavar la ropa son asuntos de las mujeres es visible que tratan de facilitar dichas actividades con el uso por ejemplo de prensa y de lavadora. Igual que en la generación adulta también en la joven existen diferencias. En Lacanjá la mayoría de las mujeres de esta generación recibió educación escolar pero solamente la minoría seguía estudiaando después de terminar la primaria. En Nahá se construyó la escuela más tarde y todavía hay familias donde no se apoyaba estudios en caso de las mujeres como podemos ver, por ejemplo, en la familia de Chan Kin (con Chan Nuk). En ambas comunidades hay mujeres que quieren trabajar y conseguir dinero (elaborando artesanías, preparando comidas) pero también algunas mujeres que prefieren quedarse en casa. Aunque dichas mujeres a veces consiguen su propio dinero en la familia todavía tienen un estatus limitado por sus maridos; por ejemplo, hasta hoy no pueden salir solas de casa, no tiene derecho a votar ni por lo común pueden realizar trabajo asalariado. Sin embargo, ya aparecen también algunas mujeres que siguen estudiando hasta la universidad y que podían conseguir trabajo asalariado fuera de su ambito familiar. Es probable que las mujeres educadas, después de sus estudios, vayan a ser ya demasiado adultas para casarse en el pueblo, si miramos las edades de casamiento y de establecimiento de las familias entre los lacandones, por lo que podrían tener problemas para casarse en su propia comunidad. Probablemente la mujer tendría otras visiones de la vida influidas por la ciudad, pero también el hombre 
apenas aceptaría una mujer con ingresos principales en la familia. En este sentido se pueden de nuevo ver diferentes trayectorias en cada familia y lo que cada una prefiere en el sentido de la educación, el trabajo y la vida familiar.

\subsection{El ámbito familiar}

Las relaciones entre los hombres y las mujeres son distintas de una familia a otra, en Lacanjá y Nahá. En la mayoría de los casos depende de las reglas que pone el jefe de cada familia, pero por la influencia de la televisión, del turismo, por el contacto con las mujeres fuereñas, las relaciones, el casamiento y convivencia han cambiado bastante. Un factor principal lo representaron también los templos evangélicos y pastores quienes pusieron limitaciones a la poligamia, al casamiento entre miembros de la misma familia y también redujeron la violencia interfamiliar (Marion, 1999).

Unos de los cambios más importalntes en el ambiente familiar se dio, por ejemplo, en el sentido de no obligar a la mujer a casarse, no aceptar que el hombre tenga más de una mujer y dar la posibilidad a las mujeres de casarse con hombres de fuera, con no-lacandones, aunque pierden el derecho de quedarse a vivir en la comunidad. McGee, en su libro Watching lacandon maya lifes, menciona que en la sociedad lacandona son considerados como Lacandones los que tienen padre lacandón (McGee, 2001).

Actualmente debido al evengelismo, el desarrollo del turismo y la llegada de las mujeres forastenas, las mujeres lacandonas ya no aceptan tan fácilmente que el hombre tenga otra mujer, aunque en ambos pueblos todavía hay un par de casos entre las generaciones adulta y joven. Si quiere tener otra esposa, el hombre deberá primero pedir permiso a la mujer que ya tiene. En Lacanjá, por ejemplo, aparecen casos en que el hombre tiene dos mujeres, pero éstas están separadas en dos casas para que no se peleen. Las dos saben de la existencia de la otra pero no trabajan juntas ni comparten la misma casa. En Nahá si el hombre tiene dos mujeres por lo general viven juntas y realizan el trabajo entre las dos.

Uno de los casos en Nahá es curioso, ya que no era el hombre quien quería tener dos mujeres, sino su mujer, para dividir el trabajo en casa. Los dos escogieron a la mujer que les parecía correcta y él fue a pedirla en matrimonio. El papá de esta mujer, al principio, no quería dársela, porque sabía que tenía otra esposa. Él regresó a casa y le dijo a su mujer mayor que no era posible. Ella le contestó que iba a arreglarlo todo. Al día siguiente la mujer habló con el padre de la otra y le explicó que ella estaba de acuerdo, así que el papá finalmente permitió que su hija se fuera a vivir con ellos. Ahora ya viven todos en la misma casa. La mujer mayor está enseñando a la más pequeña cómo hacer tortillas, a lavar la ropa, a elaborar artesanías y otras cosas de la vida cotidiana.

Es común, sin embargo, que las mujeres adultas y las jóvenes no están de acuerdo y no aceptan a otra compañera. A la pregunta de por qué, la mayoría contesta: porque tendría que dividir el dinero entre mi familia y entre la familia de la otra mujer así que yo tendría menos ropa, menos comida y mishijos también. De todas formas a muchos jóvenes les gusta bromear sobre este tema y así poner celosas a sus esposas.

Antes, los deseos y decisiones de las mujeres no importaban y lo único importante era si el hombre era capaz de trabajar, de construir una casa y de mantener a la familia. Esta regla poco a poco empezó a cambiar y hoy la mayoría de las familias la ha abandonado por completo. Hay familias donde el mayor cambio en este sentido se dio a partir de la muerte de la autoridad principal (por ejemplo la familia Chan Kin Viejo y Mateo Viejo, de Nahá), y otras en donde era importante la mudanza de Nahá a Lacanjá (como en caso de la familia Paniagua, de Vicente, Enrique y Jorge). Sin embargo, aún se dan casos en los que la mujer tiene que casarse no por deseo propio, sino por un acuerdo concertado por su padre. 
Nuk María tiene 12 años, vivía en Nahá con su papá y su madrastra. Un chico de 20 años vino a pedirla sin preguntar antes a ella. Su papá decidió casarla con él. Nuk se fue vivir con él, aprendió a preparar comida y actuar como esposa. Dejó de estudiar, dejó de participar en las clases de dibujar a las que asistía antes (en 2008) y dejó de salir sin la compaña de su esposo.

Las mujeres mayores, tanto en Lacanjá como en Nahá, se casaron por acuerdo entre el hombre y el padre. Dichas mujeres por lo general se casaban muy jóvenes y a la edad de entre 10 y 12 ya empezaban tener hijos. Como los hombres poderosos eran más grandes, a veces la diferencia en edad entre el hombre y la mujer podría llegar a ser de muchos años. No existían métodos de anticoncepción, por lo que no era nada extraño que las mujeres llegaran a tener hasta diez hijos y la diferencia entre el más joven y el mayor podría ser hasta de 20 años.

Chah Nuk de Lacanjá (aproximadamente de 60 años) se casó cuando la vino a pedir su propio abuelo. Los padres le dieron permiso y entonces empezó a vivir con él. Tuvieron una hija y él como ya era grande murió un poco después. Ella quedó viuda a la edad de 13 años.

Koh de Nahá (47 años) se casó cuando tenía solamente cinco años y se fue a vivir a la casa de Chan Kin. En la familia crecía entre los hijos de Chan hasta la madurez sexual. A la edad de 11 años cambió su estatus de hija por el de esposa. Nunca le gustó su esposo por ser mucho mayor que ella pero sabía que su opinión no importaba mucho y con el tiempo se acostumbró.

Algunas de las mujeres adultas todavía vivieron la experiencia de casarse por obligación y no por su propio gusto. Sin embargo, ellas en comparación con sus abuelas ya demostraban un poco sus deseos o desacuerdo en lo que se refiere a su futuro familiar. En algunos casos los padres no respetaban la opinión de sus hijas e intentaban forzarlas para contraer matrimonio con los que venían a pedirlas, a veces sin éxito.

Koh de Lacanjá (37 años) no se quería casar con el hombre que vino a pedirla. Sus papás no la obligaron como en algunas otras familias, pero no la podían entender. Su mamá le preguntó qué estaba buscando entonces, y le explicaba que lo más importante era que el hombre va a construir la casa y a conseguir comida para ella y su familia.

El padre de Chah Nuk de Lacanjá (26 años) quería intercambiarla con un hombre mucho mayor que ella para que así pudiera recibir a la esposa de dicho hombre. Chah Nuk tenía 11 años y no quería irse a vivir con él, pues le daba miedo estar con un hombre que no conocía. Su papá la empezó a amenazar con estrangularla si no se iba con este hombre. Su madre apoyaba en esta decisión a su esposo. Chah Nuk, entonces, escapó de la casa y empezó a vivir con otra familia que la aceptó.

Las adultas se casaban jóvenes como sus mamás pero ya no solían tener tantos hijos. Ellas por lo general ya usan algún método anticonceptivo disponible en la clínica local. Las mujeres han podido empezar a cuidarse solamente si han asistido a la clínica acompañadas de sus maridos; las mujeres jóvenes pueden venir en la compañía de sus mamás. En la clínica les piden generalmente dos firmas, la firma de la mujer misma y la firma de la mamá o, mejor, directamente del esposo. La mayoría de las mujeres de esta edad que usa anticonceptivos, prefiere el inyectable cada mes o dejan colocarse el dispositivo intrauterino por un par de años (información obtenida en la clínica).

En la generación joven se ve fácilmente la diferencia entre las mujeres ya casadas y las que siguen buscando a alguien adecuado. Se puede observar que las chicas de 15 años solteras, ya desesperadas, buscan a alguien con quien establecer la vida familiar. Como hasta ahora, en las comunidades lacandonas, no existe algo parecido al noviazgo, los jóvenes se juntan para vivir en la misma casa en cuanto sienten alguna simpatía o atracción por la otra persona, después se empiezan a conocer. Si, finalmente, descubren que la convivencia no es la correcta, a menudo ya tienen hijos y no es tan fácil cambiar el modo de la vida. Sin embargo, hay varios 
casos en que la mujer joven decide irse de la casa y deja a los niños con la familia donde vivía.

El comienzo de la vida sexual entre las jóvenes no ha cambiado mucho si lo comparamos con las otras generaciones; en Lacanjá es aproximadamente entre los 14 y 15 años, en Nahá las mujeres empiezan tener relaciones más temprano, aproximadamente desde la edad de 12 hasta 14 años (información obtenida en la clínica en Lacanjá y Nahá). En los dos pueblos hay casos de embarazo ya a la edad de 14 años. Sin embargo las jóvenes ya planean cuántos hijos quieren tener y aunque los tienen a edad temprana, por lo general no son más de 2 o 3. No es nada extraño que la mujer de 20 años ya tenga 2 hijos y no piensa tener más. La mayoría de ellas usa métodos anticonceptivos y asiste a las pláticas organizadas en la clínica.

En resumen, aunque los cambios del estatus de la mujer dentro de las familias llegan más lentamente que los cambios técnicos y comerciales, se pueden ver las diferencias entre las tres generaciones de las mujeres. El papel importante lo representó, sobre todo, la fundación de las instituciones nuevas como la escuela, la clínica y los templos protestantes, pero también el desarrollo del turismo, los medios y la conviviencia con las mujeres forasteras. Sin embargo, hay que mencionar que los cambios en las condiciones de las mujeres no han sido iguales en todas las familias. Como mencioné en el capítulo precedente, el jefe de cada familia determina las reglas y condiciones en que se desenrolla el papel de la mujer en la familia y en la comunidad. Sin embargo, el estatus de la mujer en la comunidad y en las familias particulares cambia poco a poco. Actualmente las mujeres tienen derecho de rechazar el hombre que las va a pedir, pueden cuidarse con anticoncepción y expresarse en el tema de poligamia. Las instituciones han modificado la salud en las familias, han reducido la natalidad y han dado información y educación. Una influencia importante en este sentido la tienen también los programas gubernamentales (como Oportunidades).

\subsection{Diversión y apariencia}

Las mujeres de las tres generaciones están en cierta medida fascinadas por las nuevas tecnologías que tienen en su alrededor. Casi todas las familias contemporáneas tienen la casa equipada con una televisión con DVD y un reproductor de discos de música, los cuales les ofrecen la diversión diaria. Las mujeres lacandonas adoran el mundo de las telenovelas y la mayoría de ellas las mira todos los días. Algunas mujeres me platicaban que lo que les gustaba de ellas era sobre todo el amor, los pleitos y siempre el buen final. Varias de ellas, especialmente las chicas jóvenes, están soñando que algún día venga a su comunidad un hombre guapo y rico que les muestre el mundo diferente y les compre todo lo que deseen. Hay que mencionar que no sólo las mujeres sino también los hombres ponen atención a dichos programas de televisión. Aparte de ocupar su tiempo libre, la televisión y las telenovelas mismas proponen ciertos modos de cómo vestirse, peinarse, maquillarse. Excepto las señoras mayores, que se enfocan más en el contenido de las telenovelas que en la búsqueda de inspiración, tanto las adultas como las jóvenes se dejan influir. A dichas mujeres les importa mucho la ropa y no dudan en gastar mucho dinero en su adquisición.

A Lacanjá, en comparación con Nahá, vienen mucho más vendedores; a veces compran ropa en pagos, pero después no saben donde conseguir dinero para pagarla. Hay que decir también que la ropa de la mujer refleja un poco el estatus del hombre en la sociedad ya que es bien visto que el hombre tenga a la mujer bien vestida. En ambos pueblos casi no se ve una mujer adulta o joven vestida con la túnica. Los cambios en el vestido y la diversión en general están muy vinculados con el consumo y el dinero. Los lacandones gracias al reparto de las tierras y al turismo han logrado recibir dinero y por lo general lo inverten en las cosas comerciales que les sirven, les facilitan la vida o fortalecen su estatus en la sociedad. 
Chas Nuk de Nahá (20 años), cuando era niña, vivía en la casa de Chan Kin Viejo y tenía que usar solamente la túnica pues no tenía ropa diferente. Después de la muerte de Chan Kin pidió permiso con su mamá para que pudiera eventualmente usar ropa occidental. La mamá le dio permiso y Chas Nuk empezó a vestirse diferente y le gustó. Hoy dice: "engañé a mi mamá porque ya jamás me puse la túnica”.

Las mujeres mayores por logeneral siguen vistiéndose igual que antes: dicen que se sienten más cómodas. Sin embargo, también entre ellas hay excepciones pues les encanta la moda y quieren vestirse según su gusto.

Chah Nuk de Lacanjá (aproximadamente de 50 años) vivía en la familia de Chan Kin Viejo y siempre sufría por no tener ropa, pues en la familia a los niños les dejaban siempre la ropa que se les rompía a sus mamás y no la usaban más. Dice que por esta razón ya se quería casar. Después de casarse con Kin empezó a comprar ropa y aunque todavía tiene su túnica en casa, ya no la usa.

Las imágenes y los deseos de las mujeres lacandonas están, hasta cierto punto, relacionados con los medios de comunicación y con la visión del mundo presentada por las telenovelas. Las mujeres adultas y especialmente las jóvenes se dejan influir en la aparencia y en las expectativas de la vida familiar y social. Casi todas las mujeres especialmente de la generación adulta y joven dejaron de vestirste con la ropa típica de los lacandones y prefieren la ropa del estilo occidental. Los cambios producidos por los medios de comunicación no han influido solamente a las mujeres sino también a los hombres, quienes fortalecan su estatus con nuevos carros, motocicletas, televisiones y otras cosas. Poder recibir el dinero permitió a los lacandones el paso hacia la sociedad del consumo.

\section{Conclusión}

El artículo trata de presentar los cambios que han ocurrido en la sociedad lacandona en los últimos cien años y se enfoca especialmente en la vida de las mujeres lacandonas. A través de las pequeñas biografías de distintas mujeres de tres generaciones principales estoy tratando de analizar cómo ha cambiado el estatus de la mujer en la sociedad, en distintas familias y en el mercado laboral.

Además el artículo trata el tema de poder que se está reflejando en muchos aspectos de la vida cotidiana. A través de las distintas divisiones del poder en las familias y en la comunidad se puede ver también el diferente grado e intensidad de los cambios presentados en el artículo. Traté de analizar el tema de las mujeres como un tema complejo con muchas variantes en distintas familias, donde no es fácil ver los cambios en la manera lineal sino que hay que entender distintas trayectorias dependiendo de las familias, de sus prioridades, preocupaciones, tensiones y deseos.

Las etnografías nos ofrecen algunas imágenes acerca de vida de las mujeres lacandonas en el ambiente familiar y social. El papel de la mujer era importante especialmente en el hogar en la educación de los hijos. Las mujeres eran responsables de las tareas en casa mientras los hombres trabajaban en la agricultura combinada con la caza. Además, acompañaban sus actividades diarias ocasionalmente con negocios en los campamentos de los monteros y chicleros pero también con los antropólogos y otros visitantes. Los lacandones practicaban la poligamia; el hombre tenía derecho de casarse con varias mujeres. Este tipo de matrimonio era practicado por muchas sociedades indígenas ya que les facilitaba el trabajo cotidiano. Las mujeres dividían entre ellas el trabajo diario en casa y los hombres aseguraban tener suficiente hijos y yernos para el trabajo en la milpa. A pesar de la importancia de la mujer en casa se puede ver que su participación en las actividades religiosas y su actuación fuera del hogar estaban limitadas por los miembros masculinos de cada familia. Por lo general, eran los hombres quienes se encargaban de los rituales religiosos y de los contactos con el mundo exterior. 
La vida de los lacandones, sus costumbres y actividades han cambiado significativamente a consecuencia de la concentración de las familias en los pueblos permanentes, lo que provocó frecuentes llegadas de misioneros, antropólogos y otros visistantes. Los misioneros representaron un papel especialmente importante ya que con la fundación de los nuevos templos evangelistas pusieron grandes límites en la organización familiar pero también provocaron la conversión de la gente a creencias evangélicas y el abandono de la vida ceremonial previa. Otros cambios notables están conectados con la instalación de los primeros campamentos de chicleros, pero sobre todo con el desarrollo del turismo, el reparto de las tierras y con la extensión de los medios de comunicación.

El modo de vida de los lacandones contemporáneos ha cambiado de manera importante en las áreas económica, sociocultural y familiar. Se pueden observar cambios en las formas de subsistencia y en la organizacion familiar y social. Los hombres redujeron su trabajo en la agricultura y la mayoría de ellos se enfoca más en las actividades comerciales y en el trabajo en el turismo. Las mujeres, cuya actividad principal era la preparación de los alimentos y la educación de los hijos, también poco a poco han entrado al mercado laboral. Gracias a los cambios en las tecnologías, que les facilitan las tareas en casa, pueden acompañar éstas con actividades comerciales conectadas por lo general con la venta de artesanías. Sin embargo, los cambios que han ocurrido en la sociedad lacandona no han afectado a todos igual. Los cambios esenciales se podrían dividir en dos subgrupos principales: unos en el papel principal en la autoridad de cada familia, quien pone las reglas, condiciones y hasta cierto punto determina los límites en el ambiente familiar y social; otros, que tiene que ver con toda la comunidad. En este sentido me refiero a los cambios conectados con la concentración de la gente en los pueblos permanentes, con la nueva forma de autoridad comunal y con la cercanía de las instuciones como la clínica, la escuela y el templo protestante. Sin embargo, como analizamos en este documento, en el caso de los lacandones importa más el enfoque de cada familia, frente a la comunidad en general. Eso se refleja especialmente en el estilo de vida en los grupos familiares. Los desiguales cambios se pueden ver también en las diferencias entre los grupos de edad de las mujeres.

Mediante tres generaciones de mujeres podemos ver cuáles de los cambios fueron esenciales para cada generación y hasta qué grado modificaron su vida cotidiana, su forma de subsistencia y su conviviencia familiar. En caso de las mujeres mayores, quienes crecieron en los caribales, se puede observar que hasta ahora prefieren más las tareas domésticas y el paso hacia las actividades comerciales es muy esporádico. La excepción son las mujeres viudas quienes tuvieron que buscar maneras de subsistencia también en las actividades comerciales. Así se ve que por lo general en la generación de los mayores el hombre trabaja en agricultura, combinada con actividades turísticas, y la mujer tiene la responsabilidad de las tareas domésticas. En las familias donde falta el hombre las mujeres tienen que combinar tareas en casa con actividaded comerciales, ya que necesitan mantenerse ellas misma. En caso de las mujeres adultas se puede observar el cambio hacia las actividades comerciales, que combinan con las tareas domésticas. Aunque la mayoría de dichas mujeres no tuvo educación escolar, las mujeres tratan de tener un papel activo en el turismo. Por lo general elaboran artesanías y las venden. Los hombres de dicha generación se dedican sobre todo a las actividades comerciales: venden artesanías, administran las cabañas o trabajan como guías a la selva circunstante. Cuando no hay temporada del turismo regresan a trabajar en la agricultura. La generación joven es todavía más variada. Las mujeres de dicha generación tuvieron educación escolar; pero la mayoría terminó solamente la escuela primaria. Estas mujeres por lo general siguen el modelo de sus mamás -combinan trabajo doméstico con la elaboración y 
venta de artesanías. Sin embargo, también aparecen mujeres de dicha generación que siguen estudiando hasta la universidad o tratan de buscar posibilidades del trabajo asalariado fuera de su ambiente familiar. Los hombres de dicha generación por lo general se dedican a las actividades turísticas y abandonaron el trabajo agrario casi completamente.

A través de las tres generaciónes de las mujeres podemos ver los cambios esenciales que modificaron relativamente la subsistencia y actitud de las mujeres. A pesar de esto hasta hoy los cambios más visibles son los que se conectan con economía, forma de subsistencia y con la aceptación de nuevas tecnologías. Mientras, los cambios sociales son más lentos. Las mujeres de las tres generaciones se casan muy jóvenes, en un promedio de 14 años, y ya desde esta edad empiezan formar sus propias familias. Sin embargo, la mayoría de ellas de las generaciones adulta y joven ya usan métodos de anticoncepción y planean con el marido cuántos hijos van a tener. La vida social de las mujeres sigue limitada por los hombres, hasta hoy no pueden votar sus representantes, no pueden salir solas de casa y tienen más dificultades para poder obtener un trabajo asalariado en comparación con los hombres.

El concepto del cambio cultural era el argumento importante que estudiaban varios antropólogos, sociólogos y etnólogos desde el principio del siglo XX. El propósito central era apuntar el origen y el motivo del cambio cultural. El sociólogo americano William Ogburn sostuvo que los cambios en la sociedad no se pueden ver como lineales sino que tienen en áreas económicas, sociales y familiares diferentes impactos. El caso aquí presentado podría servir para profundizar en estos análisis del cambio, de sus diversas trayectorias, ritmos y resultados. Finalmente, esto también permite cuestionar algunas ideas acerca de lo negativo que es para los lacandones (y para los indígenas en general) abandonar la vida "tradicional", es decir, que ya no quieran vestir con la túnica, que hayan abandonado su religión original o que los jóvenes se vayan de sus pueblos a buscar oportunidades fuera de la comunidad. Estos cambios, a pesar de todos los cuestionamientos, han sucedido en todas las sociedades (incluyendo las de los antropólogos) y por lo mismo no tenemos el derecho de criticarlos sin entenderlos en toda su comlejidad.

\section{Notas}

${ }^{1}$ Se incluye a mujeres y niños no lacandones.

${ }^{2}$ Se incluye a mujeres y niños no lacandones.

${ }^{3}$ Se incluye a mujeres y niños no lacandones.

${ }^{4}$ Para conocer más detalles sobre la conexión entre el mundo feminino y la cosmovisión lacandona es recomendable revisar el libro El poder de las hijas de luna (Marion, 1999).

${ }^{5}$ Otro cambio notable relacionado con el reparto de la tierra era el dinero que obtuvieron los lacandones en los años 2003 y 2004 de parte del gobierno por la invasión de otros grupos étnicos sobre las tierras de la selva. Cada jefe de familia registrado como comunero recibió un pago de aproximadamente 200 mil pesos. La gente empezó a comprar carros, televisiones, reproductores de discos de música, celulares y otras cosas. En caso de las mujeres era la ropa lo más atractivo. Según datos del campo las mujeres gastaron una buena cantidad del dinero en vestidos.

${ }^{6}$ Doña Betty es la hija adoptiva de Gertrude Duby y Frans Blom. Trabaja en la organización Na-Bolom como guía de turistas a los pueblos lacandones. $\mathrm{Na}$-Bolom tiene una casa museo hotel en San Cristóbal de Las Casas y lleva a los turistas a un campamento que tiene organización en Nahá.

\section{Bibliografía}

Baer, P., Merrifield W. (1972), Los Lacandones de México, México: Instituto Nacional Indigenista.

Blom, F., Duby G. (2006), La Selva Lacandona, México: Comisión Nacional para el Desarrollo de los Pueblos Indígenas. 
Bonfil Sánchez P., Medrano Martínek E. (2003), Diagnóstico de la discriminación hacía las mujeres indígenas, Fraccionamento Industrial Alce Blanco, Naucalpan de Juárez.

Boremanse, D. (2006), Cuentos y mitología de los lacandones, Academia de Geografía e Historia, Guatemala.

Boremanse, D. (1998), Hach Winik-The Lacandon Maya of Chiapas, Southern Mexico, Albany: Institute for Mesoamerican Studies.

Calderón, M. (2003) [1793], "Informe del padre cura de Palenque al Gobernador de Chiapas sobre la reducción de los indios lacandones, Palenque, 1793", en Jean de Vos, Viajes al desierto de la soledad, México: CIESAS, pp. 46-48.

Crehan K. (1997), The Fractured Community: Landscapes of Power and Gender in Rural Zambia, London: University of Carolina Press.

DeBoer, W. R. (1986), "Pillage and production in the Amazon: a view through the Conibo of the Ucayali Basin, eastern Peru", en World Archaeology, vol. 18, núm. 2, Weaponry and Warfare (octubre, 1986), pp. 231-246. de Vos, Jean (2006), La paz de Dios y del Rey: la conquista de la Selva Lacandona, México: Fondo de Cultura Económica. de Vos, Jean (2003), Viajes al desierto de la soledad, México: CIESAS/SEP.

Duby, G. (1961), Chiapas indigena, México: Universidad Nacional Autónoma de México

Escalona Victoria, José Luis (2009), Política en el Chiapas rural contemporáneo, México: Universidad Nacional de México.

Esteinou. R., Barros M. ( 2006), Análisis del cambio sociocultural, México: Master copy.

Gollnick, Briant (2008), Reiventing the Lacandon, Arizona: The University of Arizona Press.

Kováč, M., Podolinská T. (2001), Lakandónci: poslední praví Mayovia, Bratislava: Chronos.

Maler, T. (1898), "una visita al lago Pethá", en de Jean de Vos (2003), Viajes al desierto de la soledad, México: CIESAS/SEP, pp. 139-158.

Marion, Marie-Odile (1999), Entre anhelos y recuerdos, México: Universidad de Ciencias y Artes del Estado de Chiapas.
Marion, Marie-Odile (1990), Lacanjá Chansayab: nuevas estrategias frente al cambio social, San Cristóbal de Las Casas: Instituto de Asesoría Antropológica para la Región Maya.

Marion, Marie-Odile (1999), El poder de las hijas de luna, México: Consejo Nacional para la Cultura y las Artes/ Instito Nacional de Antropología y Historía/Plaza y Valdés

Marion, Marie-Odile (1998), Los hombres de la selva: un estudio de tecnología cultural en medio selvático, México: Instituto Nacional de Antropología e Historia.

McGee, R. J. (1990), Life, ritual and religion, California: Wodsworth.

McGee, R. J. (2002), Watching Lacandon Maya Lives, Boston: Allyn \& Bacon.

Narotzky, S. (1995), Mujer, mujeres, género, Madrid: Consejo Superior de Investigaciones Científicas.

Nolasco, M. (2008), Los pueblos indígenas de Chiapas-atlas etnográfico, México: Instituto Nacional de Antropología e Historia.

Ogburn, W. (1964), On culture and culture change, Illinois: The University of Chicago Press.

Perera, V., Bruce, R. (1982), The Last Lords of Palenque, Toronto: Little, Brown and Company

Pine, F. (1996), "Gender", en Banard A., Spencer J. (editores) Encyclopedia of Social and Cultural Antropology, London: Routlege, pp. 253-262.

Soustelle, J. (2000), Čtvero sluncí, Argo, Praha

Soustelle, J. (1934), "Los adoradores del sol", en de Jean de Vos (2003), Viajes al desierto de la soledad, México: CIESAS/SEP, pp. 195-212.

Tello Díaz, C. (2004), En la selva, México: Editorial Planeta Mexicana.

Tozzer, A. M. (1982), Mayas y lacandones: un estudio comparativo, México: INI.

Trench, T. (2002), Diagnóstico de Lacanjá Chansayab, comunidad Lacandona, municipio de Ocosingo, mcs.

Wilson, F. (1990), De la casa al taller. Mujeres, trabajo y clase social en la industria textil y del vestido, Santiago Tangamandapio, México: El Colegio de Michoacán. 